\title{
ANALISIS FAKTOR YANG MEMENGARUHI PELAYANAN ANTENATAL CARE OLEH BIDAN
}

\author{
Ainun Mardhiah \\ Program Studi D4 kebidanan Institut Kesehatan Helvetia, \\ Jalan Kapten Sumarsono No.107 Medan Helvetia Sumatera Utara, 082368288884 \\ Email : ainun.syamaun@gmail.com
}

\begin{abstract}
ABSTRAK
Keberadaan bidan di Indonesia sangat diperlukan untuk meningkatkan kesejahteraan ibu dan janinnya. Menurut WHO, setiap tahun sekitar 160 juta perempuan di seluruh dunia hamil. Para ahli menyadari bahwa persalinan akan berjalan lancar apabila adanya peningkatan pelayanan antenatal care. Tujuan penelitian ini adalah untuk mengetahui faktor pengetahuan, sikap, lama bekerja dan fasilitas kesehatan memengaruhi pelayanan ANC 10T oleh bidan Di Wilayah Kerja Puskesmas Teluk Dalam Kabupaten Simeuleu Tahun 2017. Desain penelitian adalah survei analitik dengan pendekatan cross sectional. Sampel dalam penelitian ini adalah seluruh bidan yang memberikan pelayanan ANC di Wilayah Kerja Puskesmas Teluk Dalam Kabupaten Simeuleu Tahun 2017 berjumlah 32 orang dengan menggunakan teknik sampling jenuh. Analisis yang digunakan adalah analisis univariat, bivariat dengan uji chi-square. Hasil analisis data diperoleh bahwa ada hubungan faktor pengetahuan, sikap, lama bekerja dan fasilitas kesehatan terhadap pelayanan ANC 10T oleh bidan Di Wilayah Kerja Puskesmas Teluk Dalam Kabupaten Simeuleu yaitu nilai $p=0,049$ untuk pengetahuan nilai $p=0,001$ untuk sikap, nilai $p=$ 0,01 untuk lama kerja, nilai $p=0,013$ untuk fasilitas kesehatan. Ada hubungan faktor pengetahuan, sikap, lama kerja dan fasilitas kesehatan terhadap pelayanan ANC 10T oleh bidan Di Wilayah kerja Puskesmas Teluk Dalam kebupaten Simeuleu.
\end{abstract}

Kata Kunci : fasilitas kesehatan; lama kerja; antenatal care; pengetahuan; sikap

\section{THE ANALYSIS OF INFLUENCING FACTORS OF ANTENATAL CARE SERVICE BY MIDWIVES}

\begin{abstract}
The existence of midwives in Indonesia is very much needed to improve the welfare of mothers and their fetuses. According to WHO, every year about 160 million women worldwide become pregnant. The purpose of this study was to determine the factors of knowledge, attitudes, length of work and health facilities that influence Antenatal Care services by midwives at at Teluk Dalam Health Center working area, Simeuleu Regency in 2017. The research design used was an analytic survey with the approach used in this study was cross sectional. The sample used in this study were all midwives who provided ANC at Teluk Dalam Health Center working area, Simeuleu Regency in 2017 totaling 32 people using saturated sampling techniques. The analysis used was univariate, bivariate analysis with the chi-square test. The results of the data analysis showed that there was a relationship between knowledge, attitudes, length of work and health facilities on ANC services by midwives at Teluk Dalam Health Center working area, Simeuleu Regency, namely $p=0.049$ for knowledge, $p$ value $=0.001$ for attitude, $p$ value $=0.01$ for length of work, $p$ value $=0.013$ for health facilities, each variable $P$ value $<\alpha=0.05$. The conclusion of this study is that there is a relationship between knowledge, attitudes, length of work and health facilities on ANC services by midwives at Teluk Dalam Health Center working area, Simeuleu Regency .
\end{abstract}

Keywords : attitude; health facilities; knowledge; length of work; ANC services

Jurnal SMART Kebidanan licensed under a Creative Commons Attribution-ShareAlike 4.0 International License. 


\section{LATAR BELAKANG}

Keberadaan bidan di Indonesia sangat diperlukan untuk meningkatkan kesejahteraan ibu dan janinnya. Bidan adalah orang pertama yang melakukan penyelamat kelahiran sehingga ibu dan bayinya lahir dengan selamat. Tugas yang diemban oleh bidan berguna untuk kesejahteraan manusia khususnya ibu. Keberhasilan upaya kesehatan ibu, diantaranya dapat dilihat dari indikator Angka Kematian Ibu (AKI). AKI adalah jumlah kematian ibu selama masa kehamilan, persalinan dan nifas yang disebabkan oleh kehamilan, persalinan, dan nifas atau pengelolaannya tetapi bukan karena sebabsebab lain seperti kecelakaan, terjatuh dan lain-lain (Indonesia, 2015).

Kematian ibu atau kematian maternal adalah kematian seorang ibu sewaktu hamil atau dalam waktu 42 hari sesudah berakhirnya kehamilan, tidak bergantung pada tempat atau usia kehamilan. Menurut WHO, setiap tahun sekitar 160 juta perempuan di seluruh dunia hamil. Sebagian besar kehamilan ini berlangsung dengan aman. Namun, sekitar $15 \%$ menderita komplikasi berat, dengan sepertiganya merupakan komplikasi yang mengancam jiwa ibu (Purwoastuti \& Walyani, 2015).

Angka kematian ibu (AKI) di Indonesia termasuk sangat tinggi jika dibandingkan dengan AKI di berbagai negara dalam kawasan Asia Tenggara. Seperti di banyak negara lainnya, penyebab utama kematian ibu adalah perdarahan. Perdarahan merupakan komplikasi persalinan yang dapat terjadi selama kehamilan dan pascapersalinan. Proporsi kematian yang disebabkan oleh perdarahan menempati posisi tertinggi di antara penyebab utama kematian ibu yaitu, eklampsi dan sepsis. Ironisnya semua penyebab utama tersebut, digolongkan sebagai penyulit atau komplikasi yang sebenarnya dapat dihindari apabila kehamilan dan persalinan direncanakan, diasuh dan dikelola secara benar (Purwoastuti \& Walyani, 2015).

Kematian ibu dibagi menjadi kematian langsung dan tidak langsung. Kematian ibu langsung adalah sebagai akibat komplikasi kehamilan, persalinan atau masa nifas, dan segala intervensi atau penanganan tidak tepat dari komplikasi tersebut. kematian ibu tidak langsung merupakan akibat dari penyakit yang sudah ada atau penyakit yang timbul sewaktu kehamilan yang berpengaruh terhadap kehamilan, misalnya malaria, anemia, HIVIAIDS dan penyakit kardiovaskuler (Purwoastuti \& Walyani, 2015).

Pelayanan ANC terpadu dan berkualitas adalah memberikan pelayanan dan konseling kesehatan, termasuk gizi, agar kehamilan berlangsung sehat, melakukan deteksi dini masalah, penyakit, dan penyulit/komplikasi kehamilan, menyiapkan persalinan yang bersih dan aman, merencanakan antisipasi dan persiapan dini untuk melakukan rujukan jika terjadi penyulit/komplikasi, melakukan penatalaksanaan kasus serta rujukan cepat dan tepat waktu bila diperlukan, melibatkan ibu dan keluarganya terutama suami dalam menjaga kesehatan dan gizi ibu hamil, menyiapkan persalinan dan kesiagaan bila terjadi penyulit/komplikasi (Chalid, 2015).

Para ahli menyadari bahwa persalinan akan berjalan lancar apabila adanya peningkatan pelayanan antenatal care. Hal tersebut terjadi pada tahun 1980-an seiring munculnya safe motherhood dan making pregnancy safer (Rismalinda, 2015). Sebuah program yang memastikan semua wanita mendapatkan perawatan yang dibutuhkan sehingga selamat dan sehat selama kehamilan dan persalinannnya (Indonesia, 2015).

Wanita yang mengalami keterlambatan haid minimal satu bulan dan diduga ada kehamilan sebaiknya segera memeriksakan diri ke dokter kandungan atau bidan. Hal ini perlu dilakukan untuk mendeteksi secara dini kelainan yang mungkin timbul agar dapat segera diatasi jika memungkinkan (Latief, 2016).

Upaya dalam mempercepat penurunan angka kematian ibu adalah mendekatkan pelayanan kebidanan kepada setiap ibu yang membutuhkannya, Khususnya pelayanan antenatal care. Untuk mendukung upaya kesehatan dan pencapaian sasaran pembangunan maka diperlukan tenaga kesehatan dalam jumlah, jenis dan kualitas yang tepat dan dapat diandalkan khususnya dalam akselerasi penurunan angka kematian 
ibu dan angka kematian bayi (Nurrahmaton, 2015).

Pelayanan antenatal care harus dilaksanakan secara komprehensif, terpadu dan berkualitas agar adanya masalah/penyakit tersebut dapat terdeteksi dan ditangani secara dini. Melalui pelayanan antenatal care yang terpadu, ibu hamil akan mendapatkan pelayanan yang telah menyeluruh dan terpadu, sehingga hak reproduksinya dapat terpenuhi, missed opportunity dapat dihindari serta pelayanan kesehatan dapat diselenggarakan secara lebih efektif dan efisien (Desi Wijayanti ED, 2014).

Penilaian terhadap pelaksanaan pelayanan kesehatan ibu hamil dapat dilakukan dengan melihat cakupan K1 dan K4. Pencapaian K1 dan K4 di Indonesia dari tahun 2005 sampai dengan 2015 mengalami peningkatan. Pada tahun 2005 K1 mencapai $88,60 \%$ dan K4 mencapai $77,10 \%$ sedangkan pada tahun 2015 K1 mencapai $87,48 \%$ dan K4 mencapai 95,75\%. Penilaian K4 pada provinsi Aceh merupakan urutan ke 8 paling rendah di 34 provinsi Indonesia dengan presentase $75,67 \%$. (Indonesia, 2015) Sedangkan data kabupaten Simeulue untuk persalinan yaitu jumlah ibu hamil tahun 2016 sejumlah 2.520 orang, K1 mencapai 50\% dan K4 mencapai 40\%.

Pelayanan antenatal care diberikan kepada ibu hamil yang dilakukan oleh tenaga kesehatan khususnya bidan di fasilitas kesehatan. Proses ini dilakukan selama rentang usia kehamilan ibu yang dikelompokkan sesuai usia kehamilan menjadi trimester pertama, trimester kedua dan trimester ketiga (Indonesia, 2015). Pengamatan di lapangan yang dilaksanakan oleh bidan secara intensif dalam beberapa tahun terakhir, memperlihatkan bahwa pelayanan antenatal tidak terfokus pada pelayanan $14 \mathrm{~T}$ melainkan terfokus kepada pelayanan $10 \mathrm{~T}$ (timbang, tekanan darah, tinggi fundus, tetanus toxoid, tablet tambah darah, presentase janin dan DJJ, temu wicara, tes laboratorium dan tatalaksana kasus) (Indonesia, 2015).

Berdasarkan hasil survei awal yang dilakukan peneliti pada bulan Januari didapatkan 10 bidan melakukan pelayanan antenatal care kepada ibu hamil. Terdapat 4 bidan yang melaksanakan pelananan ANC dengan 10T dan 6 bidan yang melaksanakan pelayanan dengan tidak 10T. Dengan alasan bahwa pada temu wicara tidak dilakukan dikarenakan pada saat dilakukan observasi oleh bidan tidak terdapat ibu hamil yang mengalami kelainan pada kehamilannya sehingga tidak dilakukan temu wicara. Namun jika dilihat dari pentingnya suatu temu wicara, maka sebenarnya temu wicara tersebut tidak harus menunggu adanya kelainan kehamilan.

Berdasarkan uraian di atas maka peneliti ingin melakukan penelitian dengan judul faktorfaktor yang memengaruhi pelayanan ANC oleh bidan di wilayah kerja Puskesmas Teluk Dalam Kabupaten Simeuleu tahun 2017. Tujuan penelitian ini adalah untuk mengetahui faktor pengetahuan, sikap, lama bekerja dan fasilitas kesehatan memengaruhi pelayanan ANC 10T oleh bidan Di Wilayah Kerja Puskesmas Teluk Dalam Kabupaten Simeuleu Tahun 2017.

\section{METODE}

Desain penelitian yang digunakan adalah survei analitik dengan pendekatan cross sectional (Hidayat, 2011). Populasi dalam penelitian ini adalah seluruh bidan yang memberikan pelayanan ANC dari bulan Januari sampai Mei di Wilayah Kerja Puskesmas Teluk Dalam Kabupaten Simeuleu Tahun 2017 dengan jumlah populasi 32 bidan dengan menggunakan teknik sampling jenuh (Sugiyono, 2010).

Pengumpulan data penelitian menggunakan data primer berisikan tentang pertanyaan pengetahuan, sikap, fasilitas kesehatan, dan data sekunder berupa data ibu hamil, lama bekerja dan pelayanan ANC. Analisis penelitian mengunakan system komputerisasi, berupa analisis univariat dan bivariat dengan menggunakan uji statistik chi-square derajat kepercayaan 95\% $(\alpha=0,05)$.

\section{HASIL}

Gambaran karakteristik responden pada penelitian ini meliputi umur dan pendidikan. Penelitian ini melibatkan 32 responden di 
Wilayah Kerja Puskesmas Teluk Dalam Kabupaten Simeuleu.

Tabel 1 Karakteristik Responden ( $n=32$ )

\begin{tabular}{lcc}
\hline \multirow{2}{*}{ Variabel } & \multicolumn{2}{c}{ Jumlah } \\
\cline { 2 - 3 } Umur & $\mathbf{n}$ & $\%$ \\
\hline 20 tahun & 9 & 28,1 \\
20-35 tahun & 11 & 34,4 \\
$>35$ tahun & 12 & 37,5 \\
\hline Pendidikan & & \\
D4/S1 & 17 & 53,1 \\
D1 dan D3 & 15 & 46,9 \\
\hline
\end{tabular}

Tabel 1 menunjukkan bahwa mayoritas umur $>35$ tahun yaitu 12 orang $(37,5 \%)$, pendidikan D4/S1 17 orang $(53,1 \%)$, pengetahuan kurang baik 17 orang $(53,1 \%)$, sikap negatif yaitu 19 orang $(59,4 \%)$, lama kerja $>3$ tahun 24 orang $(75,0 \%)$, fasilitas kesehatan tidak memadai 22 orang $(68,8 \%)$ dan pelayanan ANC tidak $10 T 23$ orang $(71,9)$.

Analisis bivariat dilakukan untuk mengetahui pengaruh pengetahuan, sikap, lama bekerja dan fasilitas kesehatan terhadap pelayanan ANC oleh bidan (Tabel 2).

Tabel 2 Pengaruh Pengetahuan, Sikap, Lama Bekerja dan Fasilitas Kesehatan terhadap Pelayanan ANC oleh Bidan $(n=32)$

\begin{tabular}{|c|c|c|c|c|c|c|c|}
\hline \multirow{3}{*}{ Variabel } & \multicolumn{4}{|c|}{ Pelayanan ANC } & \multirow{2}{*}{\multicolumn{2}{|c|}{ Total }} & \multirow{3}{*}{$\begin{array}{c}\text { Nilai } \\
p\end{array}$} \\
\hline & \multicolumn{2}{|c|}{ 10T } & \multicolumn{2}{|c|}{$\begin{array}{c}\text { Tidak } \\
\text { 10T }\end{array}$} & & & \\
\hline & $f$ & $\%$ & $f$ & $\%$ & $f$ & $\%$ & \\
\hline $\begin{array}{l}\text { Penge- } \\
\text { tahuan } \\
\text { Baik }\end{array}$ & 7 & 21,9 & 8 & 25 & 15 & 46,9 & \multirow{2}{*}{0,049} \\
\hline $\begin{array}{l}\text { Kurang } \\
\text { Baik }\end{array}$ & 2 & 6,3 & 15 & 46,9 & 17 & 53,1 & \\
\hline \multicolumn{8}{|l|}{ Sikap } \\
\hline Positif & 8 & 25,0 & 5 & 15,6 & 13 & 40,6 & \multirow[t]{2}{*}{0,001} \\
\hline Negatif & 1 & 3,1 & 18 & 56,3 & 19 & 59,4 & \\
\hline \multicolumn{8}{|l|}{ Lama } \\
\hline $\begin{array}{l}\text { Kerja } \\
>3 \text { tahun }\end{array}$ & 5 & 15,6 & 2 & 6,3 & 8 & 25,0 & \multirow[t]{2}{*}{0,01} \\
\hline $0-3$ tahun & 4 & 12,4 & 21 & 65,6 & 24 & 75,0 & \\
\hline \multicolumn{8}{|l|}{ Fasilitas } \\
\hline $\begin{array}{l}\text { Kesehatan } \\
\text { Memadai }\end{array}$ & 6 & 18,8 & 4 & 12,5 & 10 & 31,3 & \multirow[t]{2}{*}{0,013} \\
\hline $\begin{array}{l}\text { Tidak } \\
\text { memadai }\end{array}$ & 3 & 9,3 & 19 & 59,4 & 22 & 68,7 & \\
\hline
\end{tabular}

Tabel 2 menunjukkan bahwa ada pengaruh sikap lama bekerja dan fasilitas kesehatan dengan Pelayanan ANC dengan nilai $p$ pengetahuan $=0,049$, sikap $=0,001$, lama bekerja $=0,01$, fasilitas kesehatan $=0,013(<$ nilai a 0,05). Ada hubungan pengetahuan, sikap, lama kerja, fasilitas kesehatan dengan pelayanan ANC Oleh Bidan Di Wilayah Kerja Puskesmas Teluk Dalam Kabupaten Simeulue.

\section{PEMBAHASAN}

Hubungan Pengetahuan Dengan Pelayanan ANC $10 T$ Oleh Bidan Di Wilayah Kerja Puskesmas Teluk Dalam Kabupaten Simeuleu Tahun 2017

Pengetahuan adalah hasil pengindraan manusia, atau hasil tahu seseorang terhadap objek melalui indra yang dimilikinya (mata, hidung, mata, dan sebagainya). Dengan sendirinya pada waktu pengindraan sehingga menghasilkan pengetahuan tersebut sangat dipengaruhi oleh intensitas perhatian dan persepsi terhadap objek. (Notoatmodjo, 2014)

Pengetahuan bidan juga merupakan hasil dari tahu yang terjadi setelah melakukan pengindraan terhadap objek tertentu dan sebagian besar diperoleh melalui mata dan telinga. Pengetahuan bidan sebagian besar diperoleh dari masa pembelajaran selama proses pendidikan berlangsung dan pengalaman-pengalaman yang telah didapat selama masa bekerja. Dengan demikinan, pengetahuan dipengaruhi oleh beberapa faktor misalnya pendidikan, pengalaman, dan sebagainya. hal ini sejalan dengan hasil penelitian bahwa mayoritas pendidikan responden berada pada kategori D4 dan S2 berjumlah $53,1 \%$ dan minoritas pendidikan responden berada pada kategori D1 dan D3 berjumlah $46,9 \%$.

Peneliti berasumsi bahwa pengetahuan bidan berpengaruh terhadap pelayanan ANC 10T. Bidan yang memiliki pengetahun baik maupun kurang cenderung tidak memberikan pelayanan ANC dengan 10T kepada ibu hamil. Hal ini dapat disebabkan oleh banyak faktor salah satunya tidak mampu melaksanakan ANC dengan $10 T$ hanya melaksanakan beberapa tindakan dalam pemeriksaan ANC atau pemeriksaan dengan $7 \mathrm{~T}$. Dalam 
pelayanan ANC bahwa apabila bidan melakukan pemeriksaan ANC dengan 10T pada ibu hamil secara lengkap dapat mendeteksi secara dini jika ada komplikasi pada ibu dan anak dan juga memperkecil resiko kematian ibu dan bayi.

Berdasarkan uji Chi square yang di peroleh dalam penelitian (Panjaitan, 2013) dengan judul analisis faktor-faktor yang mempengaruhi pelaksanaan $10 \mathrm{~T}$ yang diberikan bidan pada ibu hamil Di Kecamatan Medan Marelan Tahun 2013 diketahui nilai $p=0,016$ di mana $p<0,05$ yang berarti ada pengaruh pengetahuan bidan dengan pelaksanaan $10 \mathrm{~T}$ yang di berikan pada ibu hamil.

Hasill penelitian ini juga sejalan dengan penelitian (Desi Wijayanti ED, 2014) bahwa Hasil penelitian dari 62 responden, 88,7\% bidan desa memiliki pengetahuan yang baik tentang standar pelayanan ANC. 82,3\% bidan desa melakukan pelaksanaan sesuai standar pelayanan Kebidanan yaitu $10 \mathrm{~T}$. Ada hubungan yang signifikan antara pengetahuan bidan desa tentang standar pelayanan ANC dengan pelaksanaan standar pelayanan ANC dengan $\rho$ value : 0,000 .

Hubungan Sikap Dengan Pelayanan ANC $10 T$ Oleh Bidan Di Wilayah Kerja Puskesmas Teluk Dalam Kabupaten Simeuleu Tahun 2017

Sikap menurut Maulana merupakan reaksi atau respons yang masih tertutup terhadap stimulus atau objek. Manifestasi sikap tidak dapat dilihat, tetapi hanya dapat ditafsirkan. Sikap merupakan kecenderungan yang berasal dari dalam diri individu untuk berkelakuan dengan pola-pola tertentu, terhadap suatu objek akibat pendirian dan perasaan terhadap objek tersebut. (Maulana, 2014)

Hasil uji statistik chi square pada variabel sikap responden dengan nilai $p=0,001<0,05$ yang artinya ada hubungan sikap responden dengan pelayanan ANC $10 T$ oleh bidan Di Wilayah Kerja Puskesmas Teluk Dalam Kabupaten Simeulue Tahun 2017.

Menurut asumsi peneliti bahwa sikap tergolong dalam sikap positif dan negatif. sikap positif adalah sikap yang menunjukkan penerimaan terhadap suatu objek yang harus dilaksanakan dan diterapkan dan sebaliknya sikap negatif adalah sikap yang menunjukkan penolakan terhadap suatu objek yang harus dilaksanakan dan diterapkan. Sikap bidan merupakan unsur yang penting dalam memberikan pelayanan ANC $10 T$ kepada ibu hamil, karena pelayanan yang baik bukan hanya didapatkan dari tindakan, ketelitian petugas, juga perilaku, tetapi sikap petugas sopan santun serta keramahtamahan dalam memberikan pelayanan sehingga masyarakat akan mempunyai kepercayaan yang lebih terhadap pelaksanaan pelayanan ANC 10T.

Berdasarkan penelitian terdahulu oleh (Novita, 2013) bahwa penelitian ini menggunakan uji statistik dengan chi-square test diperoleh nilai $p=0,034$ lebih kecil dari $\alpha=$ 0,05 dengan demikian hipotesa mengatakan ada hubungan antara Sikap dengan Pelaksanaan 10T Pada Ibu Hamil Di Puskesmas Sim Tim Kecamatan Simeulue Timur Kabupaten Simeulue.

\section{Hubungan Lama Kerja Dengan Pelayanan ANC 10T Oleh Bidan Di Wilayah Kerja Puskesmas Teluk Dalam Kabupaten Simeuleu Tahun 2017}

Menurut (Notoatmodjo, 2014) menyatakan bahwa pengetahuan diturunkan atau diperoleh dari pengalaman sendiri atau pengalaman dari orang lain, pengalaman bekerja seseorang dalam melakukan suatu pekerjaan memiliki kaitan terhadap hasil kerja yang dilakukan, semakin lama seseorang melakukan bidang kerja tertentu maka diharapkan bahwa hasil kerjanya semakin baik.

Masa kerja adalah jangka waktu orang sudah bekerja pada suatu kantor, badan dan sebagainya. Masa kerja (lama kerja) seseorang perlu diketahui karena dapat menjadi salah satu indikator tentang kecenderungan para pekerja. Misalnya dikaitkan dengan produktifitas kerja, semakin lama seseorang bekerja semakin tinggi pula produktivitasnya, karena akan semakin berpengalaman dalam menyelesaikan tugas yang dipercayakan padanya.

Menurut asumsi peneliti bahwa pengalaman bidan dapat diartikan bidan yang telah mempunyai waktu kerja atau masa yang dilalui 
oleh bidan dalam pelaksanaan praktik kebidanan. Bidan yang sudah mempunyai pengalaman diatas 3 tahun dapat melaksanakan praktik kebidanannya dengan baik dalam pelayanan ANC $10 \mathrm{~T}$ pada ibu hamil. Masa kerja bidan sangat mempengaruhi dengan pelayanan ANC dalam kunjungan ANC pada ibu hamil, semakin senior bidan tersebut semakin baik pelayanan yang diberikan kepada ibu hamil dibandingkan bidan yang senioritasnya lebih rendah. Dengan demikian lamanya masa kerja semakin banyak pengalaman atau pelajaran yang didapatkan, maka pelayanan ANC pun semakin baik pula sehingga dalam melakukan pelayanan pada pemeriksaan ibu hamil bidan bisa melakukan sesuai dengan standar sehingga cakupan pelayanan ibu hamil tercapai sesuai dengan yang ditetapan dan pasien mau melakukan kunjungan ulang.

Penelitian yang dilakukan oleh (Panjaitan, 2013) dengan judul Analisis Faktor-Faktor Yang Mempengaruhi Pelaksanaan $10 \mathrm{~T}$ Yang Diberikan Bidan Pada Ibu Hamil Di Kecamatan Medan Marelan Tahun 2013 diketahui nilai uji Chisquare di peroleh $p=0,002$ di mana $p<$ 0,05 yang berarti ada pengaruh masa kerja bidan dengan pelaksanaan $10 \mathrm{~T}$ yang di berikan pada ibu hamil.

\section{Hubungan Fasilitas Kesehatan Dengan Pelayanan ANC 10T Oleh Bidan Di Wilayah Kerja Puskesmas Teluk Dalam Kabupaten Simeuleu Tahun 2017}

Menurut Kohler, ada lima faktor dominan atau penentu mutu pelayanan salah satunya berwujud (Tanngieble) adalah sesuatu yang dapat terwujud seperti peralatan, penampilan petugas, kebersihan, kerapian, kenyamanan ruangan, kelengkapan, dan kesiapan petugas dalam memberikan pelayanan. Fasilitas dan peralatan berguna untuk mendukung tercapainya tujuan asuhan kebidan kehamilan sesuai dengan beban tugas bidan dan fungsi institusi pelayanan. Ketersediaan fasilitas kesehatan antara lain: tersedianya kelengkapan peralatan medis, buku-buku pedoman pemeriksaan kehamilan dan buku pedoman kesehatan lainnya serta tersedianya tempat untuk pemeriksaan.
Peneliti berasumsi bahwa fasilitas kesehatan kurang memadai dan tergolong tidak lengkap, hal ini dikarenakan kurangnya partisipasi atau kepedulian petugas kesehatan terhadap penerapan pelayanan ANC dengan $10 T$ sehingga menyebabkan petugas tidak dapat melaksanakan ANC dengan 10T. Padahal fasilitas tidak bisa dipisahkan dalam memberikan pelayanan untuk mencapai tujuan bidan dalam memberikan pelayanan sesuai dengan standar yang telah di tetapkan, oleh sebab itu fasilitas sangat penting perannya dalam memberikan pelayanan serta untuk mendapatkan hasil yang baik dalam suatu pelayanan.

Penelitian ini sejalan dengan penelitian (Novita, 2013), bahwa penelitian dengan uji statistik chi-square diperoleh nilai $p=0,005$ lebih kecil dari $\alpha=0,05$ dengan demikian hipotesa mengatakan ada hubungan antara Fasilitas dengan Pelaksanaan 10T Pada Ibu Hamil Di Puskesmas Sim-Tim- Kecamatan Simeulue Timur Kabupaten Simeulue.

\section{KESIMPULAN DAN SARAN}

Ada pengaruh faktor sikap, lama bekerja dan fasilitas kesehatan dengan pelayanan ANC dan tidak ada pengaruh faktor pengetahuan dengan pelayanan ANC oleh bidan Di Wilayah Kerja Puskesmas Teluk Dalam Kabupaten Simeuleu. Diharapkan kepada ibu hamil meningkatkan pengetahuan tentang kehamilan, melakukan pemeriksaan minimal 4 kali selama kehamilan dan kunjungan jika diketahui adanya komplikasi kehamilan.

\section{REFERENSI}

Chalid, M. T. (2015, [diunduh 29 Januari 2017]). Asuhan Antenatal Berkualitas: ANC Terpadu dan Terfokus. (http://med.unhas.ac.id).

Desi Wijayanti ED, I. S. (2014, [diunduh 20 Januari 2017]). Hubungan Pengetahuan Bidan Desa Tentang Standar Pelayanan ANC Dengan Pelaksanaan Standar Pelayanan ANC Di Puskesmas Wilayah Kerja Ibi Ranting Kendal. (http;//jurnal.akbiduniska.ac.id).

Hidayat, A. A. (2011). Metode Penelitian Kebidanan \& Teknik Analisis Data. Jakarta: Salemba Medika.

Indonesia, K. K. (2015). Profil Kesehatan Indonesia.

Latief, A. (2016). Fisioterapi Obstetri-Ginekologo. Jakarta: Kedokteran EGC. 
Maulana, H. D. (2014). Promosi Kesehatan. Jakarta: Kedokteran Buku EGC.

Notoatmodjo, S. (2014). IImu Perilaku Kesehatan. Jakarata: Rineka Cipta.

Novita, T. (2013, [diunduh 10 Februari 2017]). FaktorFaktor Penghambat Yang Berhubungan Dengan Pelaksanaan $10 \mathrm{~T}$ Pada Ibu Hamil Di Puskesma Sim-Tim Kecamatan Simeuleu Timur Kabuoaten Simeuleu (http://simtakp.uui.ac.id).

Nurrahmaton. (2015, [diunduh 20 Januari 2017]). Deteminan Kualitas Pelananan ANC Oleh Bidan Di Wilayah Kerja Puskesmas Hamparan Perak. (http://repository.usu.ac.id).

Panjaitan, M. (2013, [diunduh 20 Januari 2017]). Analisis Faktor-faktor yang Memengaruhi Pelaksanaan 10T yang Diberikan Oleh Bidan Kepada Ibu Hamil Di Kecamatan Medan Meralan.
Purwoastuti, E., \& Walyani, E. S. (2015). Ilmu Obstetri \& Ginekologi Sosial untuk Kebidanan. Yogyakarta: Pustaka Baru Press.

Rahman, R. T. (2015). Analisis Statistik Penelitian Kesehatan (Prosedur Pemilihan Uji Hipotesis Penelitian Kesehatan). Bogor: IN Media.

Rismalinda. (2015). Buku AjarAsuhan Kebidanan Kehamilan. Jakarta Timur: CV. Trans Info Media.

Setiawan, D., \& Prasetyo, H. (2015). Metodologi Penelitian Kesehatan untuk Mahasiswa Kesehatan. Yogyakarta: Graha IImu.

Sudigdo Sastroasmoro, S. I. (2016). Dasar-dasar Metodologi Penelitian Klinis. Jakarta: Sagung Seto.

Sugiyono. (2010). Metode Penelitian Kualitatif, Kuantitaf, dan R\&D. Bandung: Alfabeta. 